\title{
Fundamental Modeling of Vehicle Power Network System using VHDL-AMS
}

\author{
Shingo Ueno*, Kimitoshi Tsuji**, Takashi Abe*, Tsuyoshi Higuchi*, and Koichi Shigematsu*** \\ * Dept. of Electrical and Electronic Engineering Nagasaki University, 1-14 Bunkyo-machi Nagasaki 852-8521, (Japan) \\ ** Advanced Vehicle Control System Eng. Dev., Toyota Motor Corp., 1200 Mishuku Susono Shizuoka 410-1193 (Japan) \\ *** CYBERNET SYSTEMS CO.,LTD., FUJISOFT Bldg. 6-26, Nishiki 1-Chome Naka-ku, Nagoya, 460-0003, (Japan)
}

\begin{abstract}
The vehicle system is a multi-domain system that requires many branches of science and engineering. Therefore the development of the vehicle system requires the use of design methodologies that utilize simulations, which have grown increasingly sophisticated in recent years. This paper describes how VHDL-AMS was used to model the powertrain, alternator and battery system that are the basic elements of the vehicle power network system, and examines the simulation results with the aim of realizing a system simulation whose scope covers the entire vehicle.
\end{abstract}

Index Terms-Road Vehicles, Power system simulation, Modeling, Fuel optimal control.

\section{INTRODUCTION}

Vehicles are an essential means of transportation today, and it is not an exaggeration to say that vehicles are fundamental to social life. Vehicles not only serve as a means of transportation, but users demand certain comforts and conveniences from vehicles such as car airconditioning systems and vehicle navigation systems. The trend is for users to place increasing advanced and sophisticated demands on vehicles [1].

However, oil resources are in danger of becoming depleted and oil prices are forecasted to rise. There is also pressure to reduce the emissions of carbon dioxide that contribute to global warming. Of the 23 billion tons of carbon dioxide emitted every year, 17 percent of emissions are from road traffic, so improving road traffic can contribute to the reduction of global warming. Air pollution in major urban centers is also an extremely important environmental issue, and the need to reduce the emissions of carbon dioxide, in addition to the need to reduce traffic accidents and increase safety, are further considerations related to the use of vehicles [2].

To meet these demands, technologies related to vehicle development have continued to increase in complexity in recent years. In vehicle development, it is important during product development to examine products as a system, in addition to improving the sophistication of the individual technologies necessary for normal component design, such as electromagnetics, construction and circuits. The vehicle system is a multi-domain system that requires many branches of science and engineering, such as mechanical, heat, magnetic, hydraulic and electrochemical fields, as well as the electrical circuits and control circuits that drive them. Therefore, it is necessary to consider all of these fields equally in order to develop the vehicle as a system. Moreover, it is difficult to develop the high-mix, high-efficiency products through the traditional repetition of prototyping and testing. Therefore, the development requires the use of design methodologies that utilize simulations, which have grown increasingly sophisticated in recent years. The simulation technology available today is particularly optimized for individual elements, which are being deployed in their respective fields. However, in conducting an analysis of a multi domain system like a vehicle, it is difficult to simply exchange data between simulators due to problems with the universality of simulators. Therefore, the vehicle industry is focusing its attention on VHDL-AMS (Very High Speed Integrated Circuit Hardware Description Language-Analog and Mixed Signal) as an industry standard language certified by the IEEE [3], with various simulators supporting the language [1] [4] [5].

This paper describes how VHDL-AMS is used to model the powertrain, alternator and battery systems that are the basic elements of the vehicle power network system, and examines the simulation results with the aim of realizing a system simulation whose scope covers the entire vehicle.

\section{Modeling of Vehicle System}

The schematic diagram of the vehicle system simulation model in this paper is shown in Fig. 1. The powertrain means the power transmission device or drive device, and serves the purpose of transmitting the mechanical energy generated by the engine to the drive wheels that actually drive the vehicle. The components of the powertrain include the engine, clutch, transmission, and propeller shaft. Mechanical energy generated by the engine is converted into electrical energy by the alternator. The electrical power generated by the alternator is supplied to the electric and electrical components via the battery.

The followings are the detailed modeling using VHDL-AMS for the powertrain, alternator, battery systems and load, which are the four elements of the vehicle power network system. In this research, SIMPLORER by Ansoft Corporation was used as a circuit simulator that supports the use of VHDL-AMS.

\section{A. Powertrain Mdeling}

In the powertrain model, the engine rotational speed is calculated using the vehicle running speed as the input. Equation (1) is used for the calculation. 


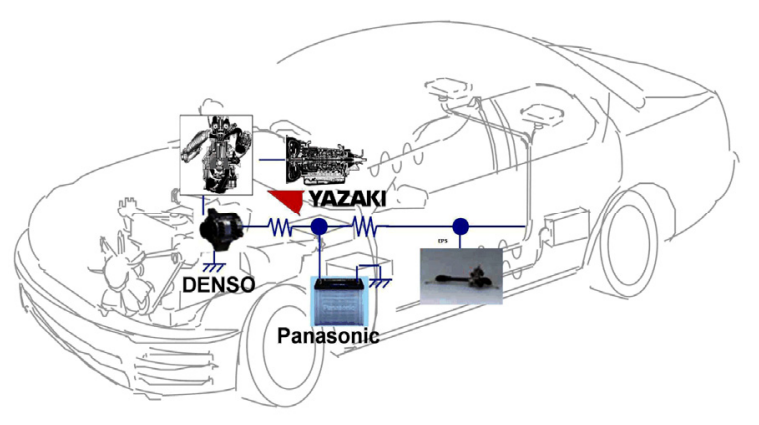

Fig. 1. The schematic diagram of the vehicle system simulation model.

$n=\frac{V \times 1000}{60 \times 2 \pi r} \times i_{m} \times i_{f}$

Where, $n$ is the engine rotational speed [r/min], $V$ is the vehicle running speed $[\mathrm{km} / \mathrm{h}], r$ is the effective tire radius of the drive wheel $[\mathrm{m}], i_{m}$ is the gear ratio, and $i_{f}$ is the final reduction gear ratio, respectively. The Japanese 10-15 mode was used for the vehicle running speed profile, and the gear position for the vehicle speed was chosen based on reference [6].

\section{B. Alternator Mdeling}

The alternator is a claw-pole type field synchronous generator with field winding. But for the purpose of simplification, the modeling was conducted using the combination of a three-phase synchronous generator, shown in Fig. 2, and a three-phase full-wave rectifier circuit. The schematic model of the alternator is shown in Fig. 3, and part of the description of the alternator by VHDL-AMS is shown in Fig. 4. Using VHDL-AMS, the modeling of the generator can be simply described using a voltage equation and equation of motion. It is also possible to model by using a look-up table of experimental data or analysis data.

\section{Battery Modeling}

Lead-acid storage battery is widely used in today's vehicles. The battery construction is shown in Fig. 5. The chemical reaction of the battery electrodes causes the acidic concentration to be lower near the electrodes in the discharge state. The diffusion of acidic molecules between the upper and lower concentration regions was modeled using the equivalent circuit shown in Fig. 6, by using diffusion resistance, in addition to a slow- and fastcharging and discharging capacitor [7]. Part of the model description by VHDL-AMS using the equivalent circuit from Fig. 6 is shown in Fig. 7.

The important characteristics of the battery are the current, voltage and state of charge (SoC) that indicates the charge state. The SoC is calculated using the equation below. The charge state of the battery is expressed as the charge quantity stored in the capacitor. $Q_{\text {init }}$ is the initial charge quantity stored in the battery, $Q_{\max }$ is the maximum charge quantity that the battery can be stored, and $Q_{\text {total }}$ is the variable charge from charging and discharging. Additionally, $v_{\text {init }}$ is the initial battery voltage and $v_{\max }$ is the maximum battery voltage.

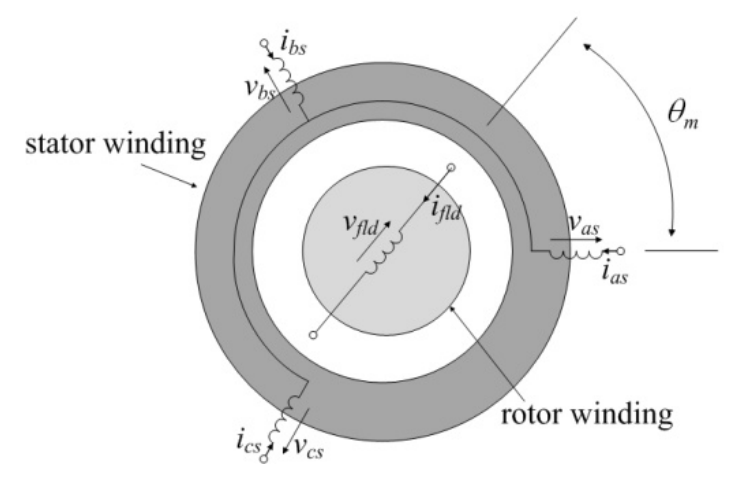

Fig. 2. Three-phase synchronous generator model.

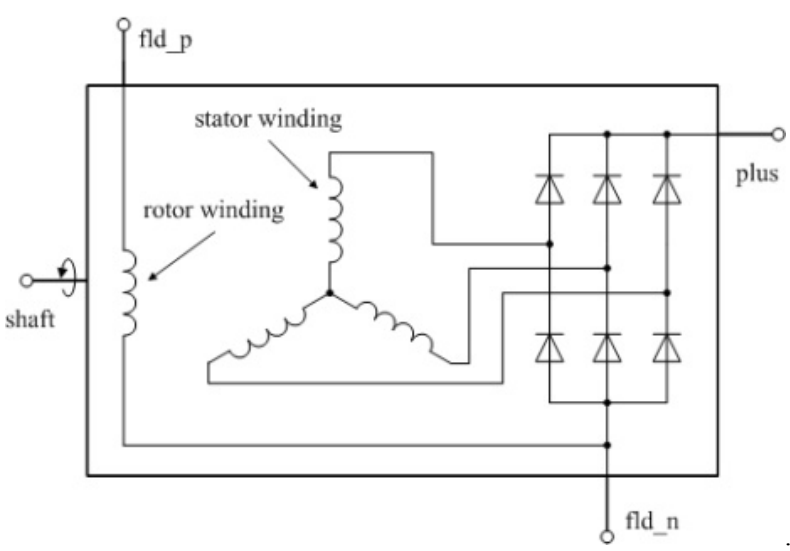

Fig. 3. The schematic model of the alternator.

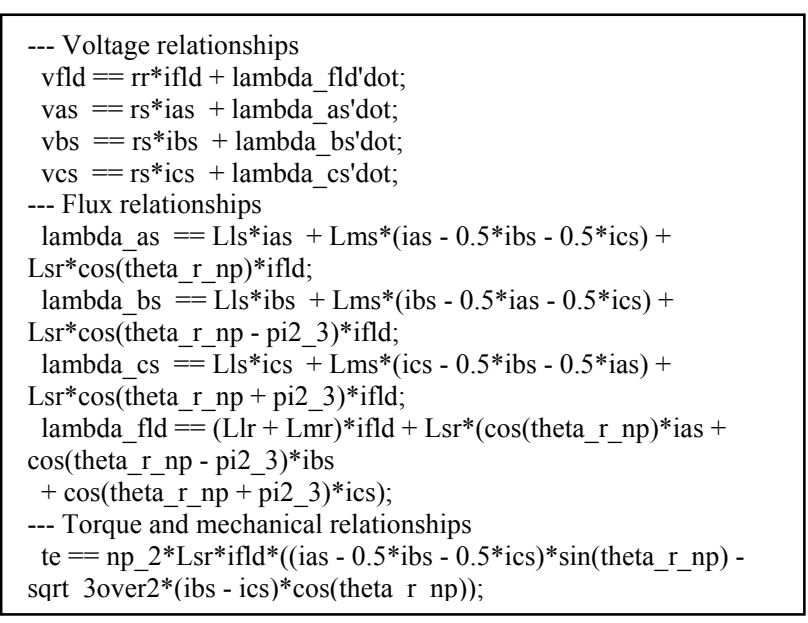

Fig. 4. The description by the VHDL-AMS for the alternator (one part).

$\left.\begin{array}{l}Q_{\text {init }}=\left(c_{f}+c_{s}\right) \cdot v_{\text {init }} \\ Q_{\text {max }}=\left(c_{f}+c_{s}\right) \cdot v_{\max } \\ Q_{\text {total }}=c_{f} v_{c f}+c_{s} v_{c s}\end{array}\right\}$

$S o C=Q_{\text {total }} / Q_{\max }$ 


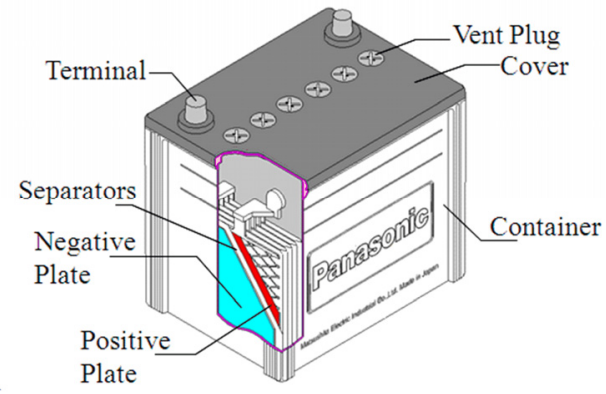

Fig. 5. Typical battery construction.

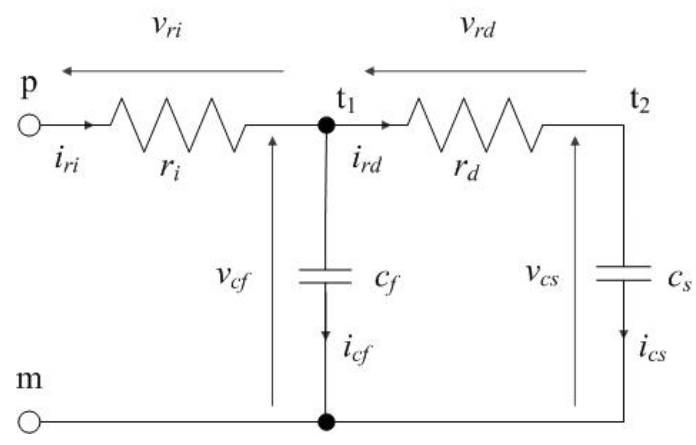

Fig. 6. Equivalent circuit of the battery.

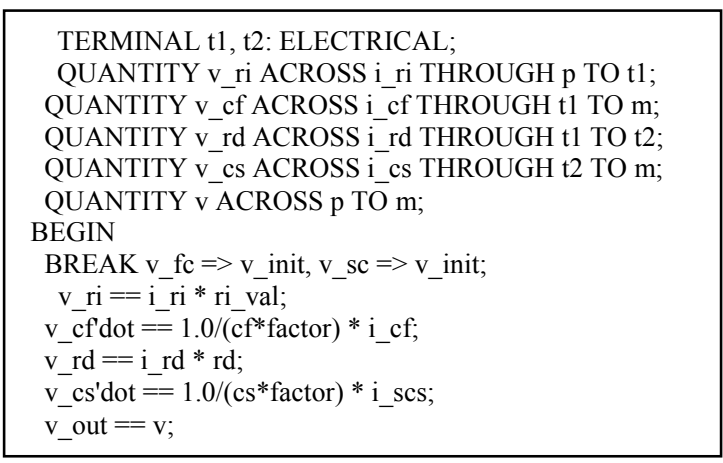

Fig. 7. The description by the VHDL-AMS for the battery (one part).

\section{Load Modeling}

For this research, the load was modeled as ideal resistance. For the electrical load, $R_{1}$ is $0.9 \Omega$ and $R_{2}$ is 7 $\Omega . R_{1}$ is equivalent to using the lights and air-conditioning, and $R_{2}$ simulates the hazard lights [8].

\section{E. Vehicle Power Network System Model}

The vehicle power network system model is shown in Fig. 8. This model is comprised of the powertrain, alternator, battery and load, as already described. As shown in Fig. 8, DATA model is used to input the vehicle running speed into the powertrain model. In the DATA model, the Japanese 10-15 mode speed profile is used. In the powertrain model, the rotational speed is calculated for input into the alternator model. In accordance with the calculated rotational speed, the output voltage and output current are calculated in the alternator model. In the same manner, the current and voltage for the battery and electrical load are calculated in accordance with the alternator output.
In this way, the vehicle power network system becomes a multi domain system, and the powertrain model is a mechanical domain using a rotational angle, and the battery and load are the voltage and current of the electrical domain. The alternator uses the rotational angle as input and the voltage as output, and is the interface for the electrical domain and mechanical domain.

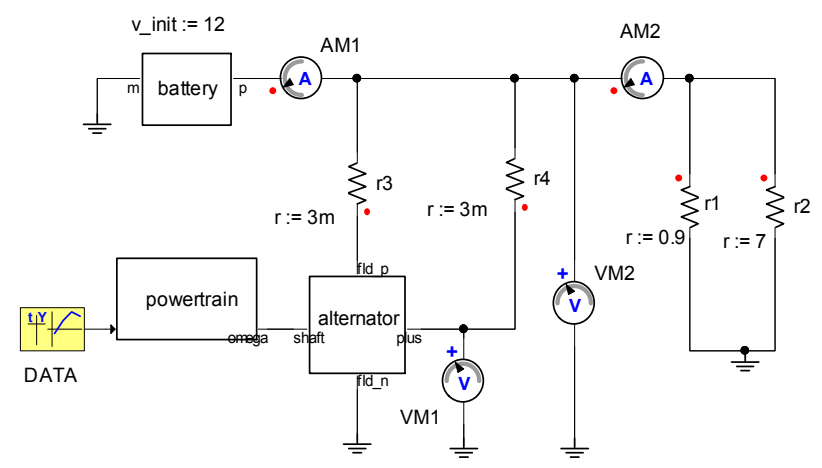

Fig. 8. Vehicle power network system model.

\section{ANALYSIS RESUltS}

The simulation was executed using an initial battery voltage of $12 \mathrm{~V}$. In addition, other parameters for the synchronous generator and battery were set based on reference [6]. The battery supplies electrical power to the load when the alternator output voltage is low, and supplies current to the field winding of the alternator when the engine starts. However, when the rotational speed rises and the alternator output voltage increases, the alternator supplies the load and field current. Using these conditions, the analysis results based on the Japanese 1015 mode driving pattern are shown in Fig. 9(a)-(g). When the vehicle running speed is $0 \mathrm{~km} / \mathrm{h}$ or the clutch is disengaged, the engine rotational speed is $0 \mathrm{r} / \mathrm{min}$ [(Fig. 9(b)]. At the engine rotational speed is $0 \mathrm{r} / \mathrm{min}$, SoC characteristic in Fig. $9(\mathrm{~g})$ are shown to decrease. Furthermore, the battery current in Fig. 9(e) is shown to be a positive value, from which it can be understood that the battery supplies electrical power to the load when the engine rotational speed is $0 \mathrm{r} / \mathrm{min}$. Conversely, when the engine rotational speed increases, SoC characteristic in Fig. $9(\mathrm{~g})$ are shown to increase. Furthermore, the battery current in Fig. 9(e) is shown to be a negative value, from which it can be understood that the alternator supplies electrical power to the battery and load. A constant field current, in Fig. 9(f), is supplied from the battery when the engine rotational speed is $0 \mathrm{r} / \mathrm{min}$. When the engine rotational speed increases, the value of the field current increases. This is because the alternator output current increases according to the engine rotational speed increases, and the alternator supplies a current to the field winding. In an actual vehicle, the alternator uses a voltage regulator to control the field current value in order to maintain the output voltage within the default value range. However, the voltage regulator is not considered in this simulation model. 


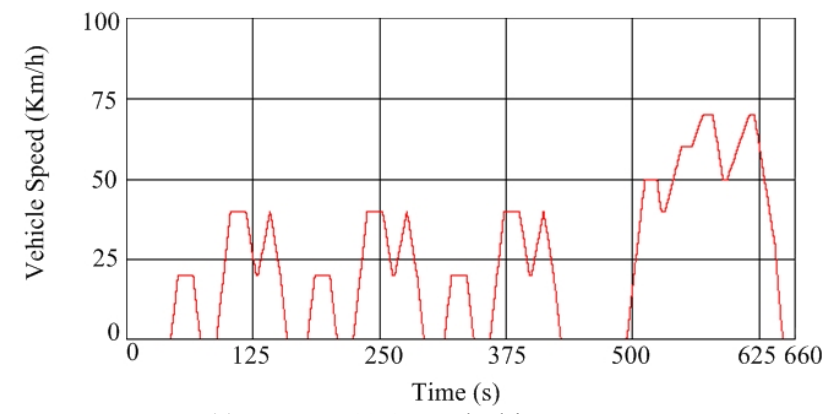

(a) Japanese 10-15 mode drive pattern

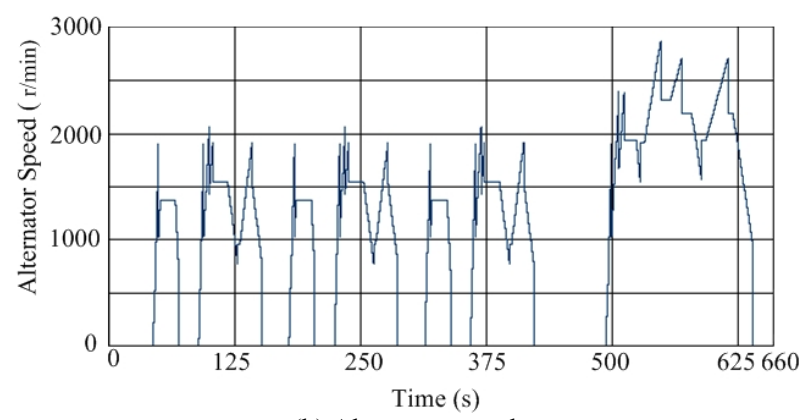

(b) Alternator speed

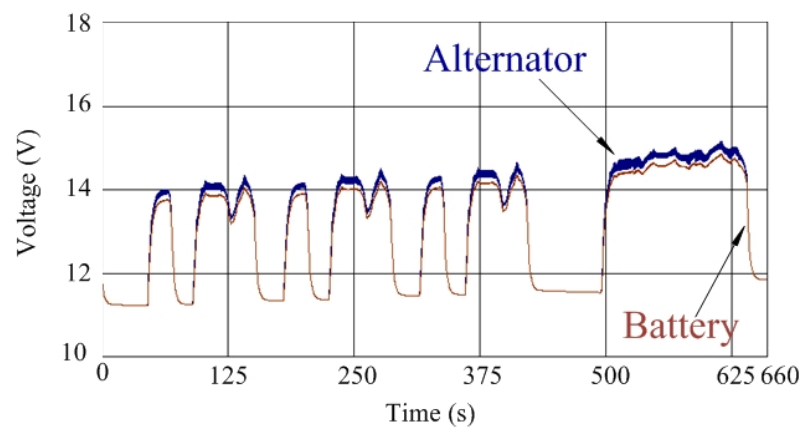

(c) Alternator and battery Voltage

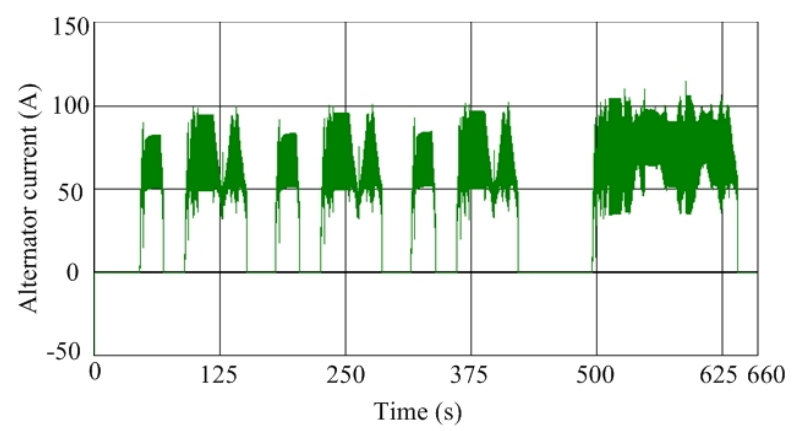

(d) Alternator current

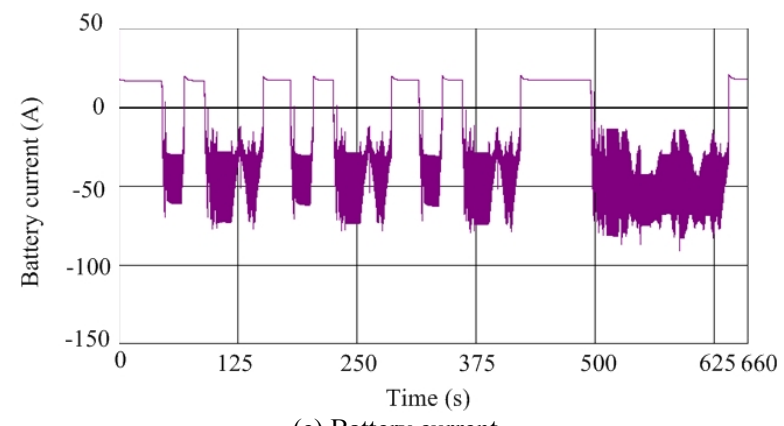

(e) Battery current

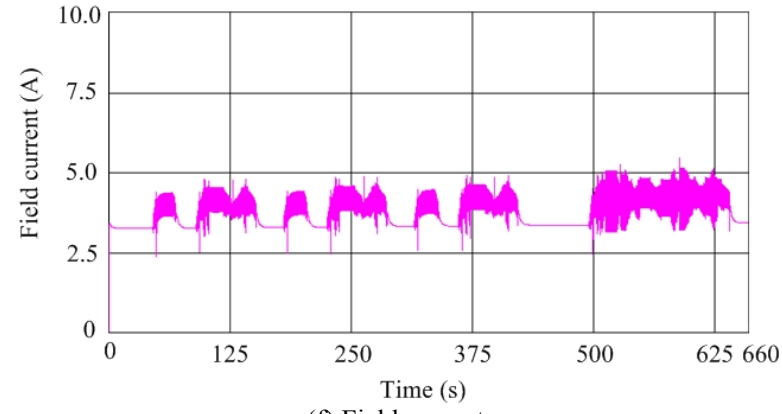

(f) Field current

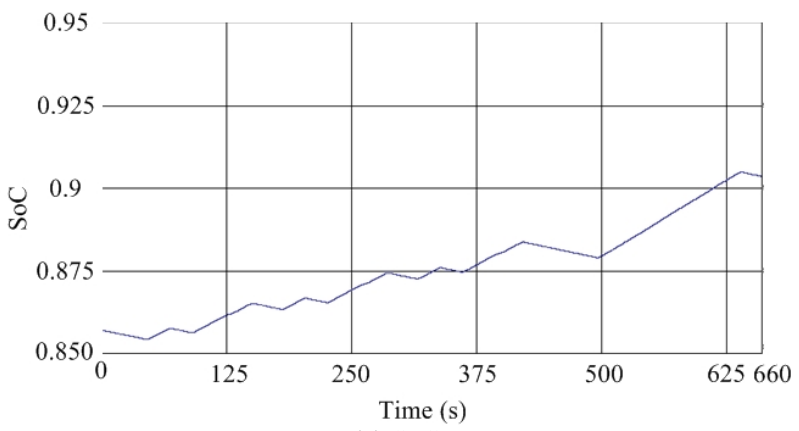

(g) SoC

Fig. 9. Analysis results.

\section{FUEL CONSUMPTION MODELING}

The fuel consumption is calculated using equation (4).

$f_{t}=\frac{f \cdot P}{3.6 \times 10^{6}}$

Where, $f_{t}$ is the fuel injection $[\mathrm{g} / \mathrm{s}], f$ is the fuel consumption $[\mathrm{g} / \mathrm{kWh}], P$ is the engine power [W], respectively. The fuel consumption calculated using general fuel efficiency contour line is shown in Fig.10, and the engine power is calculated using equation (5) [9].

$$
P=2 \pi n T / 60
$$

Where, $T$ is the engine torque $[\mathrm{Nm}]$ which is calculated using equation (6).

$$
F=T i_{m} i_{f} \eta / r
$$

Where, $F$ is the vehicle driving force $[\mathrm{N}], \eta$ is the mechanical transmission efficiency, respectively.

When the Vehicle runs on the flat road, the running resistance is generated. The vehicle driving force and the running resistance are related to equation (7) during constant speed driving, and are also related to equation (8) during acceleration driving condition.

$$
\begin{aligned}
& F=\mu_{r} M g+\kappa v^{2} \\
& M \alpha=F-\left\{\mu_{r} M g+\kappa v^{2}+\left(M+M_{r}\right) \alpha / g\right\}
\end{aligned}
$$

Where, $\mu_{r}$ is the coefficient of friction, $M$ is the vehicle mass $[\mathrm{kg}], \kappa$ is the coefficient of air friction, $v$ is the vehicle running speed $[\mathrm{m} / \mathrm{s}], \alpha$ is the acceleration $\left[\mathrm{m} / \mathrm{s}^{2}\right]$, 
$M_{r}$ is equivalent mass for the rotational inertia and $g$ is gravitational acceleration $\left[\mathrm{m} / \mathrm{s}^{2}\right]$, respectively.

The analysis results based on the Japanese 10-15 mode driving pattern are shown in Fig. 11 and Fig. 12. In Fig. 11 , the vehicle is idled while the vehicle stops and in Fig. 12 , the vehicle is stopped idling while vehicle stops. The fuel injection shown in Fig. 11 and Fig. 12 increase during the acceleration driving. It is thought that this is sake of the acceleration resistance to occur at the acceleration processes. The final fuel consumption was improved from $16.49 \mathrm{~km} / 1$ to $17.97 \mathrm{~km} / 1$ by stopping idling.

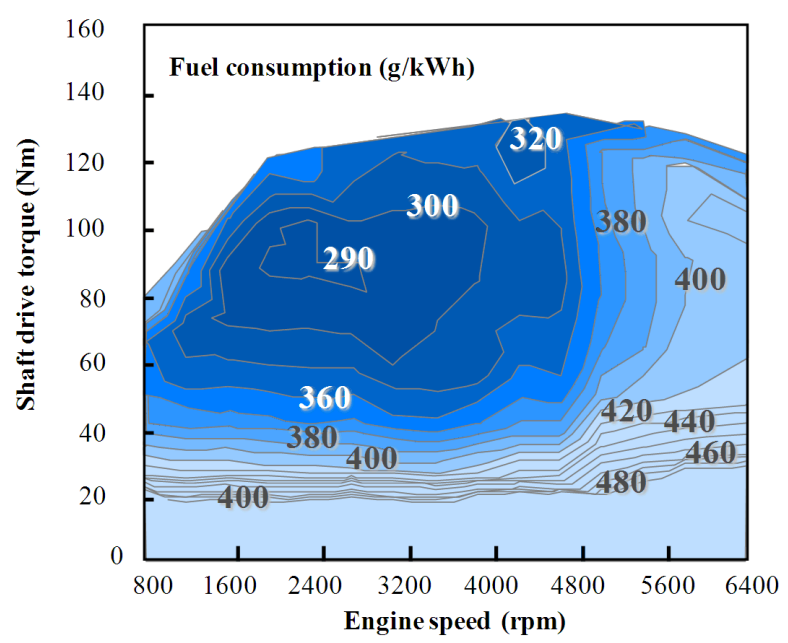

Fig. 10. Fuel efficiency map.

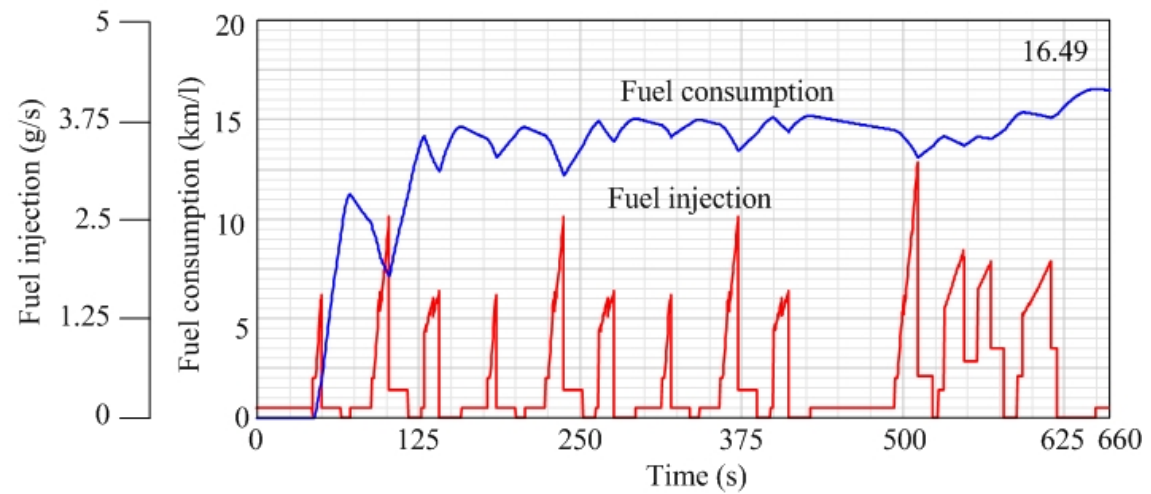

Fig. 11. fuel consumption (idling).

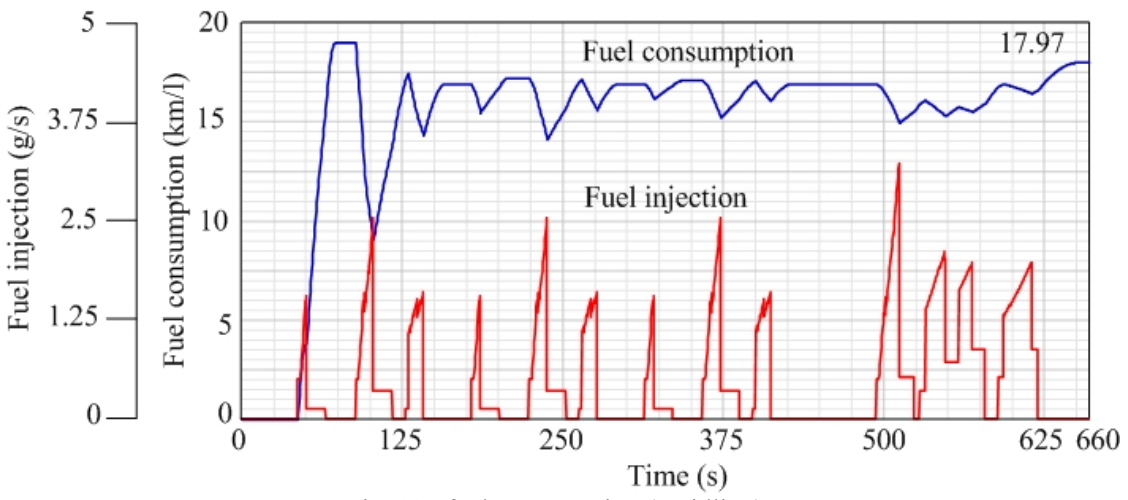

Fig. 12. fuel consumption (no idling).

\section{CONCLUSION}

This paper showed VHDL-AMS modeling of the powertrain, alternator, battery and load which are the basic elements of the vehicle power network system. The modeling results showed that VHDL-AMS is useful for conducting a vehicle system simulation. To further expand the vehicle power network system, these researchers will integrate a voltage regulator that was not considered in this simulation.

\section{ACKNOWLEDGMENT}

For the vehicle system simulation, Tsuji who belongs to Toyota Motor Corporation gave us technical advice. Ansoft Japan also has provided technical support on SIMPLORER. Thanks for the cooperation.

\section{REFERENCES}

[1] K. Shigematsu, T. Sekisue and K. Tsuji : "Auto-motive System Simulation", 2006 National Convention Record IEE Japan IAS, Vol.1, No.S9-3, pp.1-6 (2006)

[2] S. Ookuma, T. Teratani, K. Nozaki, H. Iwano, T. Nagaoka, O. Hurukawa, M. Konisi, K. Yamada, K. 
Shigematsu, H. Nakamura : "Electronics innovation in the automobile (Japanese only) "NTS inc. (2004)

[3] IEEE:"IEEE Standard VHDL Analog and MixedSignal Extensions", IEEE Std 1076.1-2007, ISBN: 07381-5627-2 (2007)

[4] Society of Automotive Engineers of Japan : "Simulation technology of the automotive development (Japanese only)" Asakura Publishing Co., Ltd. (1997)

[5] K. Tsuji, T. Abe : "On the Simulation Method for Automotive Power Network System using VHDLAMS", 2008 National Convention Record IEE Japan IAS, Vol.1, No.S9-3, pp.1-6 (2006)

[6] Japanese Standards Association : "JIS handbook automobile I" Japanese Standards Association, pp.930-932(2007)

[7] Ansoft Corporation : "SIMPLORER VHDL-AMS TUTORIAL" (2003)

[8] N. Nagashima, R. Ochiai, G. Fujita, T. Fukada : "Development of Simulation Model for Vehicle's Electrical Power System", 2008 National Convention Record IEE Japan IAS, Vol.2, No.59, pp.533-534 (2008)

[9] Kimitoshi Tsuji, Michito Enomoto, Takashi Abe"Analysis of Alternator Regeneration using VHDL-AMS vehicle system simulation",the 34th Annual Conference of the IEEE Industrial Electronics Society, HF-005843, pp.2788-2793 (2008) 